\title{
Skeletal Manifestations of Tuberculosis in Modern Human Remains
}

\author{
MARYNA STEYN ${ }^{1} *$ AND JENIFER BUSKES $^{1,2}$ \\ ${ }^{1}$ School of Anatomical Sciences, University of the Witwatersrand, Parktown 2193, South Africa \\ ${ }^{2}$ Department of Anatomy, University of Pretoria, Private Bag X323, Arcadia 0007, South Africa \\ *Correspondence to: M. Steyn, School of Anatomical Sciences, University of the Witwatersrand, 7 York Road, \\ Parktown 2193, South Africa. E-mail: maryna.steyn@wits.ac.za
}

\begin{abstract}
Paleopathologists study the presence of diseases in the past and as such have a vast knowledge of skeletal changes associated with different conditions. Tuberculosis is one of the most studied diseases and still remains a major health problem today. Its manifestations in past populations have been extensively described, but less is known about its bony involvement in the post-antibiotic era. The aim of this study was to assess the frequency and manifestations of skeletal lesions in the post-antibiotic era in a South African sample and compare it to that found before the introduction of antibiotics. Skeletons of 205 individuals from modern skeletal collections and who are known to have died from TB were assessed. It was found that $39.2 \%$ of all individuals dying in the post-antibiotic era showed skeletal changes that could be associated with TB, while another $27.5 \%$ showed nonspecific changes. The highest incidences were found in individuals who died after 1985, when coinfection with HIV and drug resistance became common. While, as expected, vertebral and rib changes were the most common, the number of individuals who showed changes to the skull, and specifically intracranially, was surprising. These could most probably be associated with TB meningitis, although this specific cause of death was noted in only a few individuals. It seems that individuals may be living longer as a result of long-term antibiotic use, leaving more time for lesions to develop. Clin. Anat. 29:854-861, 2016. (C) 2016 Wiley Periodicals, Inc.
\end{abstract}

\section{INTRODUCTION}

Palaeopathologists aim, among other things, to elucidate past incidences of disease and to study the influence of disease on the history of populations and mankind in general (Angel, 1981; Ortner, 2003). By studying old documents, human skeletal remains and other tissues from past populations, much can be learned about the natural progression of disease before the intervention of modern medicine, and in the case of infectious diseases, antibiotics in particular. Although the study of diseases in antiquity has obvious limitations such as difficulties in making an exact diagnosis, it has added much to our understanding of human health and disease and the fragile balance between micro-organisms, their hosts and the 
environment. This is also true for tuberculosis (TB), a disease of which the origin, influence throughout history, and general epidemiology have been extensively studied.

TB remains a massive problem world-wide, and in South Africa, it is the leading cause of natural deaths (Kanabus, 2011; Pillay et al., 2013). It has shown considerable increases in the past few decades, not least because of frequent co-infection with Human Immunodeficiency Virus (HIV). An estimated 14 million people world-wide were co-infected with HIV and TB by 2012 (Pawlowski et al., 2012), making HIV the single most important risk factor for contracting TB. HIV is also frequently the cause of progression of dormant disease into full-blown TB and causes rapid progression of the disease. HIV-related TB is the most common in sub-Saharan countries, making up $79 \%$ of such cases known world-wide (Naidoo et al., 2011). TB is now also the most common cause of HIV-related deaths, and occurs in at least one-third of HIV-positive people in sub-Saharan Africa (Kanabus, 2011; Pillay et al., 2013).

Knowledge of the past incidences and signs of TB as well its spread can help us to better understand this condition. Some recent studies seem to point to Africa as the original source of this disease (Daniel, 2006; Wirth et al., 2008; Bos et al., 2014), but in South Africa there is currently no clear skeletal evidence of its existence before contact with western societies, and its emergence and spread seems to be mostly associated with the mining history of the country. Of course, the absence of evidence does not necessarily indicate evidence of absence (Roberts and Buikstra, 2003). A possible but unconfirmed case of precontact TB in South Africa was found in the North-West province and dates back to the late 1700s (Pistorius et al., 1998). Of the five archaeological cases identified with possible TB in the Campbell and Ackermann (2010) study, three were from post-contact contexts, one was the male mentioned above from the North-West Province, while the other one was only indicated to be of rural context.

TB and its manifestations in the human skeleton have been studied extensively in past populations, but much less is known about its expression in the skeleton in the postantibiotic era and if, in fact, the introduction of antibiotics changed its expression in any way. A notable exception here is the study by Holloway et al. (2013), that showed that bony tuberculous lesions can heal (especially following antibiotic treatment), and that this may complicate the diagnosis of TB in skeletons as, usually, TB is not associated with new bone formation but rather bony destruction. Recently, Steyn et al. (2013) reported on trends in bony involvement of skeletons from patients who are known to have died from TB. In this study, skeletons $(n=147)$ from the northern region of South Africa were studied and comparisons were drawn with regard to the skeletal manifestations of TB between individuals who died before the introduction of antibiotics (estimated to be around 1950), and those who died thereafter. A group of individuals dying after 1985, broadly judged as the time when co-infection with HIV became common and drug resistance developed, was also included.

In the study by Steyn et al. (2013), it was found that about one third of all skeletons showed signs that could be associated with TB-this is much higher than the $2-4 \%$ that is generally reported in the literature (Vigorita, 2008; Holloway et al., 2011), but it should of course be kept in mind that these are people who have died from TB and do not represent the patient 
cohort at large. Skeletal involvement increased from the pre-antibiotic period (around $21.1 \%$ of individuals), to $38.2 \%$ and $41.0 \%$ in the pre- and post- 1985 skeletons, respectively. It was proposed that people are now living longer with their TB as a result of receiving antibiotic treatment, thus allowing more time for skeletal lesions to develop. Similar to what was found in another study by Holloway et al. (2011), it was also found that rib lesions are becoming more common, while spinal lesions seem to be decreasing. The Holloway et al. (2011) study, however, was a meta-analysis of cases reported in the literature and did not include any remains from post-antibiotic contexts. It should be kept in mind that there are many factors that may play a role in the expression of this disease. As is the case with many other diseases and micro-organisms, Mycobacterium tuberculosis undergoes continuous evolution (Barnes, 2005) and the co-evolution of the disease and it host has most probably also changed the expression of TB in the skeleton.

TB in skeletal remains is most commonly characterized by involvement of the vertebral bodies, with destructive lesions most often occurring in the vertebral bodies of the thoracic and lumbar regions (Resnick and Niwayama, 1988). The neural arches are mainly unaffected (although they may play a role in the healing of TB lesions; Holloway et al., 2013), and the subsequent collapse of the vertebral bodies often leads to kyphosis of the spine commonly referred to as Pott's disease (Ortner, 2003; Roberts and Buikstra, 2003). Virtually any part of the skeleton can be affected, but the most commonly affected regions include the ribs, sacro-iliac, femoral and knee joints, or any other joint. However, as is commonly the problem in paleopathology, lesions are often nonspecific, and it is difficult to find lesions that are truly pathognomonic of TB, or for that matter, any infectious disease in skeletal remains (Wilbur et al., 2009). In the study by Steyn et al. (2013), it was found that nearly a quarter of individuals showed nonspecific lesions which could not directly be associated with TB, suggesting that widespread skeletal involvement may occur but only later develop in lesions that could specifically be associated with TB, or that coexistence with other conditions is common.

The Steyn et al. (2013) study was done on a relatively small sample $(n=147)$ and only included individuals from the Gauteng (northern) region of South Africa. The purpose of this article is twofold: first to report on the findings from an expanded sample which also includes specimens from the southern part (Western Cape) of the country. These skeletons come from a different context-although it is a somewhat sweeping assumption, the skeletons from the northern region that end up in collections can most probably often be associated with miners from the Gauteng region (thus slightly higher SES); the skeletons from the Cape are most probably of people of very low SES and there are no extensive mining activities in this region. Unfortunately, little is known about the background of the individuals in these collections, and assumptions on life style can only be made in a broad context. It is not sure if this, in itself will make a difference, but the Western Cape remains may to some extent reflect the skeletal expression of people of extremely low SES, possibly plagued by malnutrition and often with high levels of alcohol consumption (Schneider et al., 2007). The second aim of the article is to reflect on some of the skeletal changes observed in the skeletons from the post-antibiotic era and assess whether these are generally the same as those observed in pre-antibiotic specimens. 


\section{MATERIALS AND METHODS}

The study included skeletons from collections at the University of Pretoria (The Pretoria Bone Collection; L'Abbé et al., 2005), University of the Witwatersrand (Raymond A Dart Collection; Dayal et al., 2009), University of Stellenbosch (Kirsten Collection), and the University of Cape Town. These collections are cadaver based, and mostly include individuals who are unclaimed and are, therefore, donated to the universities by various hospitals. They are all known individuals, with known age, sex, and cause of death.

Skeletons of individuals reported to have died from TB were analyzed. The sample from Gauteng included 147 individuals (134 males and 13 females) (Steyn et al., 2013), whereas the Western Cape sample included 58 individuals and comprised 43 males and 15 females. All available individuals were used regardless of their age, sex, and ancestry but were not included if the remains were very incomplete or fragmentary. As these collections are of modern individuals and cadaver-based, preservation was in most cases excellent.

The skeletons were systematically analyzed and signs that could be associated with infectious disease were documented. No bone samples were taken and no destructive analyses were performed. Skeletal elements were scored as present or absent. Similar to the methodology followed by Steyn et al. (2013), all observed lesions were judged as to whether they could be due to TB. As pointed out before, it is very difficult to diagnose any specific disease and thus it was also difficult to determine whether a lesion is due to TB or not and many lesions could only be classified as nonspecific. These mostly comprised periostitis, often observed on the long bones. New bone formation/plaques on the visceral surfaces of ribs or rib expansion (Pfeiffer, 1991), lytic lesions of the vertebrae and clear joint destruction or other lytic lesions were classified as lesions being due to TB. TB mostly causes destructive lesions, with limited new bone formation (Ortner, 2003), although attempts at healing especially in the post-antibiotic era can complicate the assessment (Holloway et al., 2013).

The sample was divided into three groups based on their date of death - those who died before 1950 (1925-1949) and who probably did not receive any antibiotic treatment, those who died between 1950 and 1985 assumed to have been treated with antibiotics, and those who died after 1985 when co-infection with HIV and drug-resistant TB emerged. The date 1950 is used as post-antibiotic as Streptomycin was introduced in the late 1940s and 1985 is used (somewhat arbitrarily) because the first cases of drug-resistant TB and co-infection with HIV in South Africa were reported around that time (Steyn et al., 2013). Unfortunately, all of the Western Cape skeletons dated from the antibiotic period. Results from the various time periods were then compared by means of a Chi-squared analysis. Assessments were also made with regard to where lesions occurred, and if the same patterns of skeletal involvement occurred in the different groups.

\section{RESULTS}

As is often the case with paleopathological investigations, it is very difficult to assign a lesion to a specific disease. In this study all cases were donated from hospitals and had firm diagnoses of TB, but nevertheless all lesions could not directly be ascribed to TB as one 
should keep in mind that these individuals may have been malnourished (contributing to subperiosteal bone deposition) or may also have suffered from other diseases including treponemal disease and HIV (with nothing known about the skeletal signs of HIV, other than assuming that HIV in itself will probably not lead to specific bony changes, but rather that any changes may be due to the opportunistic infections associated with this condition). Unfortunately all Western Cape individuals in the collection $(n=58)$ died after 1950, but were equally distributed between pre- and post-1985 specimens.

In the combined sample, with all cases from both regions, it can be seen that individuals with skeletal signs of TB increased from $21.1 \%$ in the pre-antibiotic period to $28.6 \%$ (individuals dying 1950-1985) to $46.7 \%$ (individuals dying after 1985) (Table 1). The overall increase seen in skeletal lesions associated with TB is mostly statistically significant (pre1950 and 1950-1985: $\chi^{2}$ value $=0.831, P=0.362 ;$ pre-1950 and post-1985: $\chi^{2}$ value $=9.170$, $P=0.0025 ; 1950-1985$ and post-1985: $\chi^{2}$ value $\left.=5.091, P=0.0241\right)$. In addition to these, about one quarter of all other individuals had other signs of skeletal involvement, mostly comprising nonspecific periostitis on long bones.

Table 1. Western Cape and Gauteng Combined Sample: Frequency Distribution of Individuals Showing No Signs of TB (No Skeletal Involvement), Nonspecific Signs of Infectious Disease and Signs of TB

$\begin{array}{lcccc} & \text { Total } \boldsymbol{N} & \boldsymbol{N} \text { (Unaffected) } & \boldsymbol{N} \text { (Nonspecific) } & \boldsymbol{N}(\text { TB) } \\ \text { Pre-1950 } & 52 & 29(55.8 \%) & 12(23.1 \%) & 11(21.1 \%) \\ 1950-1985 & 63 & 27(42.9 \%) & 18(28.6 \%) & 18(28.6 \%) \\ \text { Post-1985 } & 90 & 24(26.7 \%) & 24(26.7 \%) & 42(46.7 \%) \\ \text { Total } & 205 & 80(39.0 \%) & 54(26.3 \%) & 71(34.6 \%)\end{array}$

This increase in bony involvement is especially obvious in the Western Cape group (Table 2), where only $17.2 \%$ of individuals dying from 1950 to 1985 showed signs of skeletal TB, increasing to $58.6 \%$ in those dying after $1985\left(\chi^{2}\right.$ value $=10.068, P=0.0015$ between Affected vs. Unaffected individuals; $\chi^{2}=13.646 ; P=0.0002$ between TB specific lesions vs. unaffected individuals.) In this group, about one third of other individuals showed nonspecific signs of infectious disease. Overall, taking all individuals with TB in the post-1950 era into account, no statistically significant differences were found between the Western Cape and Gauteng groups for TB-specific individuals $\left(\chi^{2}\right.$ value $\left.=0.875 ; P=0.3496\right)$.

Table 2. Frequency Distribution of Individuals Who Showed no Skeletal Signs of Disease, Those With Nonspecific Signs of Disease and Those With Skeletal Signs of TB in the Specific Eras in the Western Cape Sample Only

$\begin{array}{lcccc} & \text { Total } \boldsymbol{N} & \boldsymbol{N} \text { (Unaffected) } & \boldsymbol{N} \text { (Nonspecific) } & \boldsymbol{N}(\mathrm{TB}) \\ 1950-1985 & 29(50 \%) & 14(48.3 \%) & 10(34.5 \%) & 5(17.2 \%) \\ \text { Post-1985 } & 29(50 \%) & 3(10.3 \%) & 9(31.0 \%) & 17(58.6 \%) \\ \text { Total } & 58 & 17(29.3 \%) & 19(32.8 \%) & 22(\%)\end{array}$

In the Steyn et al. (2013) study, it was proposed that there may be an increase in rib lesions (occurring in $23.8 \%$ of all individuals; in $20 \%$ of post antibiotic individuals but becoming more frequent if only individuals with skeletal changes are taken into account) and a decrease in vertebral lesions (occurring in $8.8 \%$ of all individuals; in $4.2 \%$ of post-antibiotic 
individuals) with time. This trend was not so clear in the Cape skeletons where overall $27.6 \%$ of individuals had rib involvement and $13.8 \%$ had spinal involvement. These individuals were all post-antibiotic and this observation needs to be followed up with larger samples.

An unexpected observation was the frequent involvement of the skull, with overall 10 individuals (7.0\%; 142 individuals with skulls) from Gauteng and 6 individuals $(10.0 \% ; 50$ individuals with skulls) from the Western Cape with some sort of cranial lesion (for this calculation it should be kept in mind that some skulls were absent). Of these lesions, six were on the cranial vault, of which some may possibly have been the result of other diseases (e.g., lesions resembling a gummatous lesion possibly resulting from treponemal disease). A case with extensive periostitis on the outside of the skull on one side and a destructive lytic lesion on the other side is shown in Figure 1. One case of intra-cranial involvement appeared to have originated from a possible otitis media as the destructive lesion is situated in the petrous bone (Fig. 2). Quite frequently, though, and observed in 9 cases, were extensive destruction of the cranial base (Figs. 3 and 4; see also Fig. 4 in Steyn et al. 2013). In only one of these cases was the posterior cranial fossa involved, whereas in the others the middle and anterior cranial fossae were affected. The severe and destructive nature of these lesions is clear from these two images.

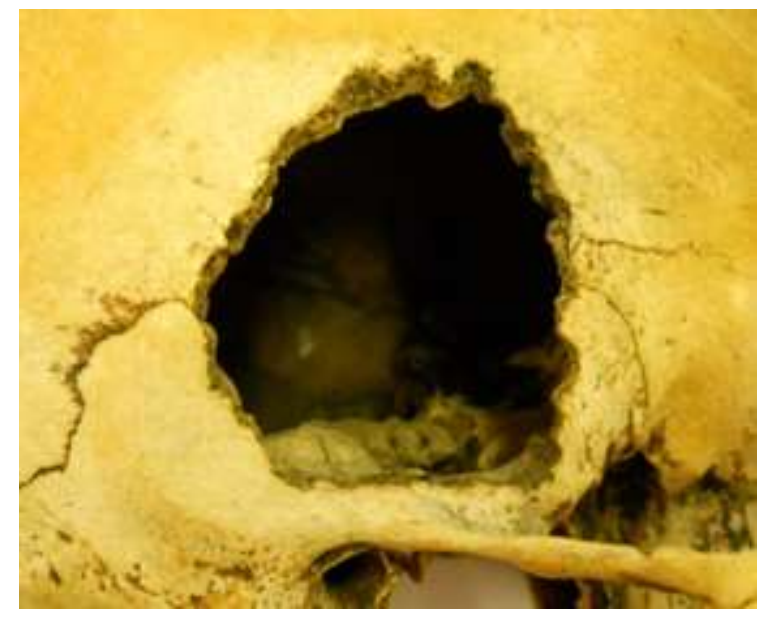

Figure 1. Destructive, lytic lesion in the cranial vault of individual A175 (50-year-old male).

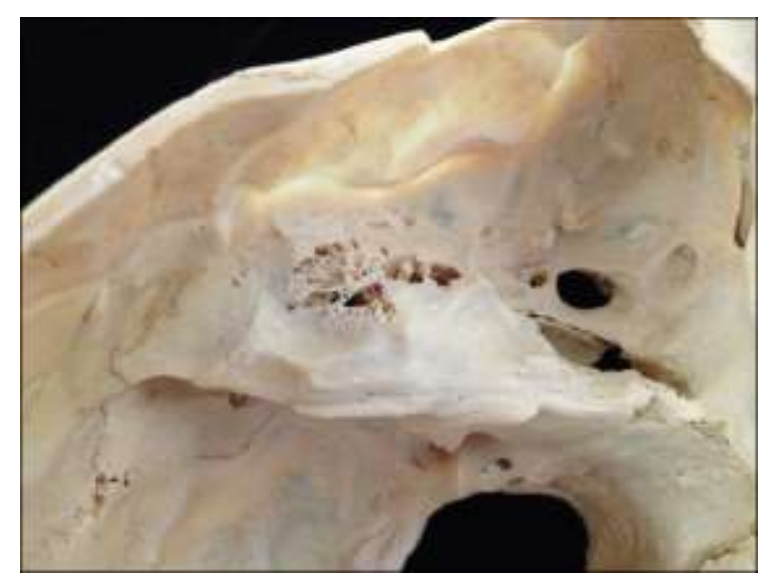

Figure 2. Intracranial lesion possibly originating from otitis media (40-year-old male; case number AN 881). 


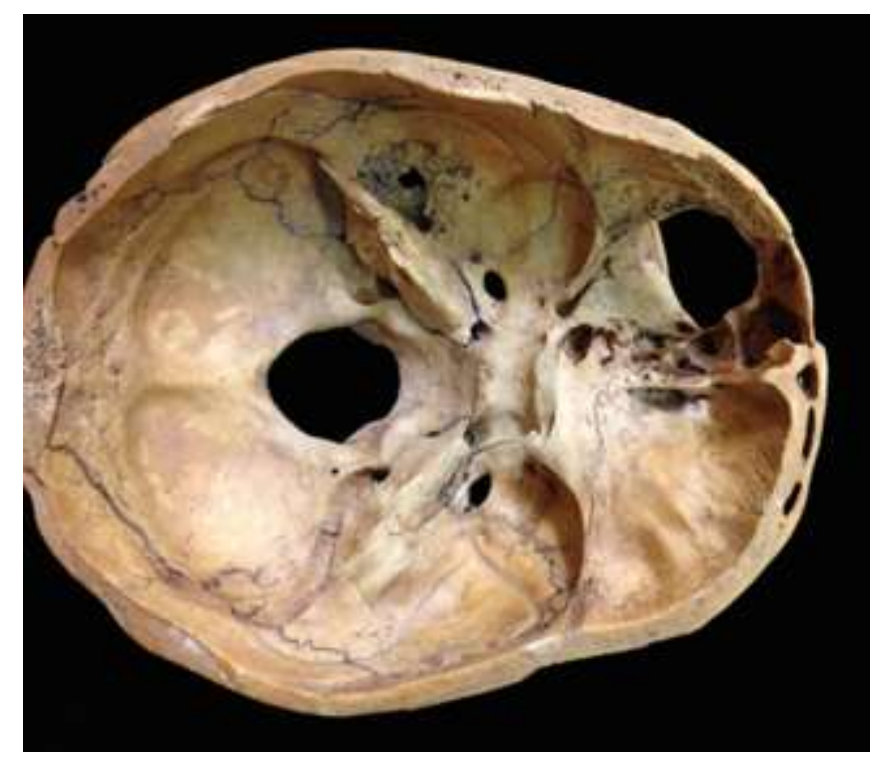

Figure 3. Destruction of the anterior and middle cranial fossae in a 37-year-old male (Case 03-88; date of death 1988).

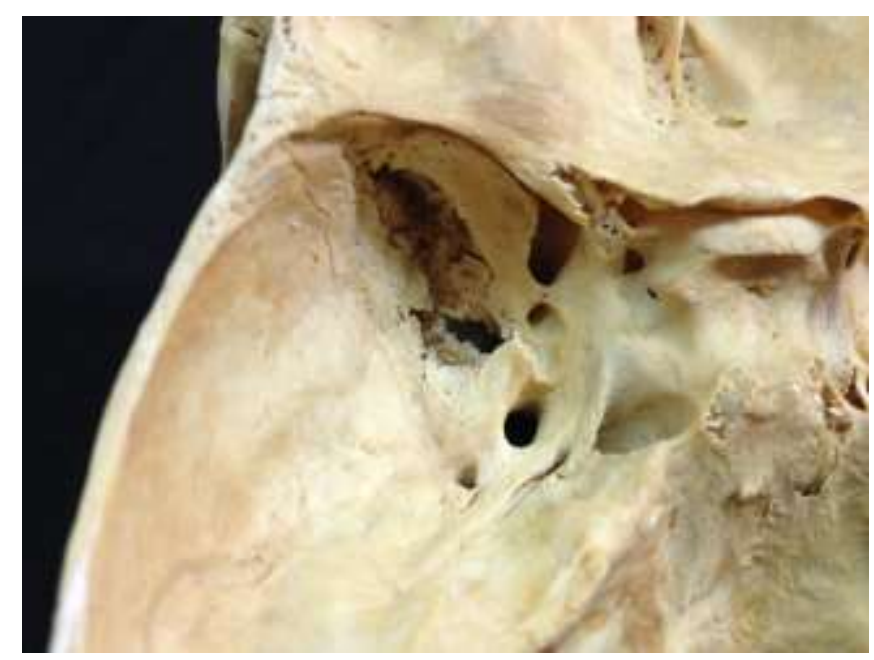

Figure 4. Destruction of the middle cranial fossa in a 46-year-old male (Case 55-08; date of death 2008).

Surprisingly, a high frequency ( $n=6 ; 11.5 \%$ out of the 52 with mandibles) of mandibular condyle destruction was observed in one or both sides. In some of these cases, the individual was edentulous which may have contributed to the destruction of the mandibular condyle, and it also seems unlikely that TB of the temporomandibular joint (TMJ) would occur on both sides. In the case shown in Figure 5 (a 33-year-old male with teeth), however, it seems likely that the changes are due to TB. This individual has complete destruction of the right mandibular condyle, with surrounding periostitis. Few sources reported on the involvement of the TMJ and TB in paleopathology while in contrast, some cases have been reported in the clinical literature. It is rare that the TMJ is affected by TB due to the absence of abundant cancellous bone in the mandible (Karjodkar et al., 2012). The clinical literature, however, describes it as erosion or destruction of the condyle which can be visualized with CT scans and the presence of TB was then confirmed with histology (Prasad et al., 2007; 
Patel et al., 2012). The diagnosis depends on the physician and some consider it to be tuberculous osteomyelitis (Karjodkar et al., 2012; Sheikh et al., 2012), while others consider it to be extra-pulmonary TB (Prasad et al., 2007; Helbling et al., 2010; Patel et al., 2012).

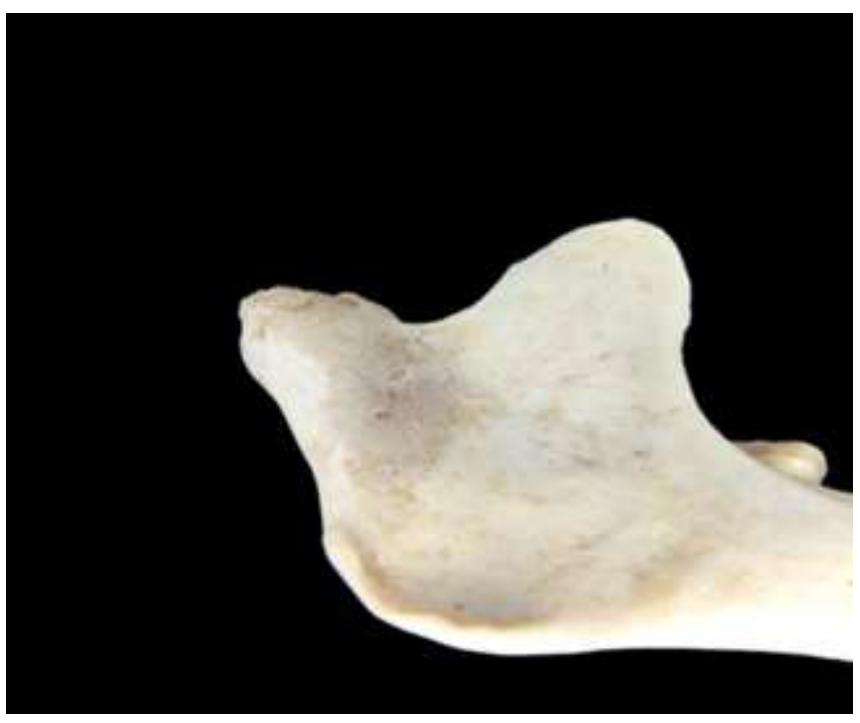

Figure 5. Destruction of the mandibular condyle in a 33-year-old male (case AN 429); date of death 1976. Note the complete destruction of the condyle, with periosteal reaction surrounding it.

In general, destruction of joints was rarely seen in our sample, but if present could involve any of the large joints with no clear pattern seen. An example of severe destruction of the femoral/hip joint is shown in Figure 6. Tuberculous lesions are uncommon on the shafts of long bones, but Figure 7 shows a very interesting case of a lytic lesion in the shaft of the ulna. A sequestrum (dead piece of bone) can clearly be seen in the centre of this lesion, with surrounding bone showing attempts at repair and periosteal reaction.

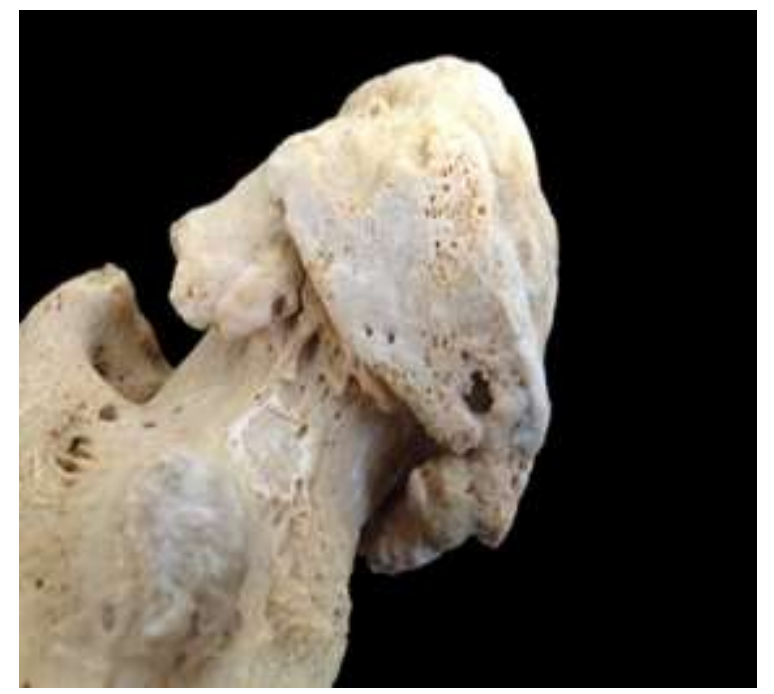

Figure 6. Destruction in a hip joint (38 year old male; AN 881; date of death 1988). 


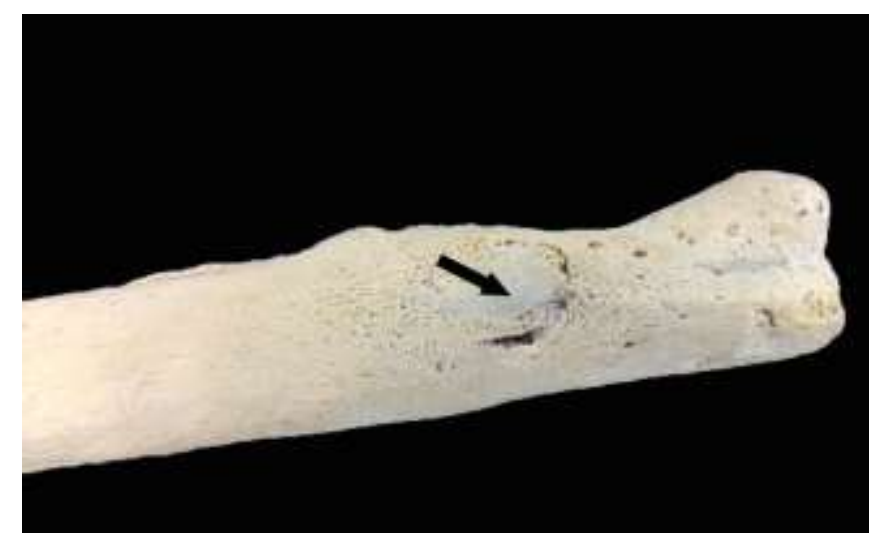

Figure 7. Lesion in shaft of distal ulna. The arrow indicates a sequestrum, surrounded by new bone formation (32-year-old female, AN 276).

\section{DISCUSSION}

Severe destructive lesions of bone, resulting from TB, are commonly associated with historic or prehistoric specimens, but it is seldom that one considers the extent and implications of these in modern individuals. From this study, it is clear that skeletal lesions frequently occur in modern cases of TB, despite the antibiotic treatment. This is contrary to our expectations that antibiotic treatment should reduce this extensive spread of the disease. In fact, it seems that skeletal involvement may be becoming more frequent, as the figures reported here show a rise in the involvement of the skeleton, and are also higher than that reported in the literature on historic cases (Holloway et al., 2011). It is well known that there is a high incidence of noncompliance regarding the completion of antibiotic treatment, and this may in fact lead to an increase in skeletal lesions with partial healing taking place in some individuals. One should also possibly consider the effectiveness of current antibiotic treatments, and the fact that they may not penetrate bone sufficiently. If patients do not complete their medication, the possibility should be considered that bony lesions may not have cleared up completely and that the disease may reactivate from there. It should be noted that in this study no attempt was made to distinguish between healed, healing and active lesions.

Other reasons for the high incidence of TB associated lesions in this study may include changes in strain lineages, as well as the co-infection with HIV. As mentioned in Steyn et al. (2013), it is possible that mixed infections (as experienced in HIV) may change the host resistance and thus lead to different clinical presentations of the disease. What is clear, though, is that many of the lesions seen are quite extensive and destructive, and would contribute considerably to the suffering of the patient.

The high incidence of cranial lesions, and specifically of the anterior and middle cranial fossae, is interesting and can most probably be associated with TB meningitis (TBM). The skull is usually reported as a rare site of skeletal involvement, mostly occurring in young adults and mostly on the cranial vault (Aufderheide and Rodriguez-Martin, 1998; Ortner, 2003). It was also interesting to note that in only two of the cases with intracranial involvement from Gauteng, was TB meningitis recorded as the cause of death, whereas it was not reported as cause of death in any of the Western Cape cases. These lesions in the 
post-antibiotic group was relatively more common in the Western Cape group, where it is known that there are high reported incidences of TBM (at least in children) and also much drug resistance.

Most knowledge of the pathogenesis of TB meningitis stems from the work of Rich and McCordock (1993), where they used rabbits and guinea pigs to show that simple hematogenous spread of TB bacilli did not lead to TBM but direct inoculation into the central nervous system was needed. It was discovered that a meningeal focus was able to grant the bacilli access to the subarachnoid space and thereby induce meningitis. This focus became known as the "Rich focus", which is a caseating vascular lesion located in the cortex of the brain or the meninges (Rock et al., 2008). It is thus thought that Rich foci follow a vascular pattern and therefore bacteremia - the presence of viable bacilli in the circulating blood (Rippey, 1994) - leads to dissemination of the TB bacilli. Highly oxygenated areas of the body are frequently involved including the brain and the development of a Rich focus in the brain, spine or meninges marks the beginning of TBM (Rock et al., 2008; Shankaragouda et al., 2013). The rupture of a Rich focus leads to the clinical manifestations of TBM. It has also been found that tumour necrosis factor (TNF- $\alpha$ ), which plays a role in granulation formation of TB, alters the blood-brain-barrier permeability and along with cerebrospinal fluid (CSF) leukocytosis, may enhance the progression of TBM (Rippey, 1994; Rock et al., 2008). TB bacilli may replicate inside macrophages once ingested and within the CNS, microglial cells are the resident macrophages and thus immunosuppressive effects may be induced. Thus, it has been postulated that bacilli may traverse across the endothelial barrier or may enter the subarachnoid space via passage of infected macrophages (Rock et al., 2008).

Once bacilli gain access to the subarachnoid space, gelatinous exudates form and are most frequently found in the interpeduncular fossa, the anterior suprasellar region and it may extend throughout the prepontine cistern and surround the spinal cord (Rock et al., 2008). These exudates may also be found in the basilar areas due to the normal flow of CSF-thus possibly explaining the involvement of the cranial base seen in this study. TBM is also frequently associated with miliary TB which may indicate a pathogenetic relationship. The presence of miliary TB in TBM was concluded to increase the probability that a Rich focus will develop and rupture (van den Bos et al., 2004).

In summary, it has been postulated that TBM is due to the hematogenous spread of bacilli from a primary complex, which then forms a Rich focus and subsequently proceeds to caseate and release its contents into the subarachnoid space; alternatively a Rich focus may form in the choroid plexus or in the walls of the ventricle, or caseating material may be released from adjacent structures such as the vertebrae or the middle ear which then involves the CNS (Donald et al., 2005).

Young children, mostly those younger than 4 years old (De Souza et al., 2014), and patients co-infected with HIV patients are at high risk of developing TBM. The high incidence of cranial involvement in our study supports the fact that adults are also at high risk, probably associated with HIV co-infection. Other risk factors include malnutrition, recent measles in children, alcoholism, malignancies, and the use of immunosuppressive drugs in adults (Rock et al., 2008). The commonest cause of adult meningitis in Soweto, South Africa, was found 
to be TBM and it was related to poor compliance or drug-resistant TB (Karstaedt et al., 1998). The highest incidence of TBM in children exists in the Western Cape in South Africa (van den Bos et al., 2004). Although the literature does not mention the exact pathogenesis of how TB causes lesions in the skull, the mechanism might be similar to that of soft tissue pathogenesis, given there is enough time to allow for bony manifestations to form.

The respective cases of TB infection of the temporomandibular joint and through otitis media reported on here are unusual. Although it has been described in the clinical literature, it is to our knowledge the first such cases described on skeletal remains alone.

In summary, this article demonstrated that skeletal involvement in individuals dying from TB is still very much prevalent, although the frequency of lesions should be interpreted considering the fact that these are people who have died from the disease, and cannot necessarily be directly extrapolated to living people with the disease. However, it has some interesting clinical implications both as far as patient suffering and possible reactivation of TB from bony lesions are considered. It seems as if the prolonged treatment with antibiotics may in fact contribute to an increase in skeletal lesions, and it may be that patients are living longer with their disease thus providing more opportunity for skeletal lesions to develop. Indeed, it may be true that we make them live longer but they suffer more.

\section{ACKNOWLEDGMENTS}

The authors would like to thank the curators of the Raymond A. Dart, Pretoria Bone, Kirsten and University of Cape Town collections for access and permission to study the remains. The authors are also indebted toward Deona Botha and Yvette Scholtz for their invaluable contributions. The research of M. Steyn is supported by the National Research Foundation of South Africa (NRF). Any opinions, findings, and conclusions expressed in this article are those of the authors and, therefore, the NRF does not accept any liability in regard thereto.

\section{REFERENCES}

Angel JL. 1981. History and development of palaeopathology. Am J Phys Anthropol 56:509-515.

Aufderheide AC, Rodriguez-Martin C. 1998. The Cambridge Encyclopedia of Human Paleopathology. Cambridge: Cambridge University Press.

Barnes E. 2005. Diseases and Human Evolution. Albuquerque: University of New Mexico Press.

Bos KI, Harkins KM, Herbig A, Coscolla M, Weber N, Comas I, Forrest SA, Bryant JM, Harris SR, Schuenemann VJ, Campbell TJ, Majander K, Wilbur AK, Guichon RA, Wolfe Steadman DL, Cook DC, Niemann S, Behr MA, Zumarraga M, Bastida R, Huson D, Nieselt K, Young D, Parkhill J, Buikstra JE, Gagneux S, Stone AC, Krause J. 2014. Pre-Columbian mycobacterial genomes reveal seals as a source of New World human tuberculosis. Nature 514:494-497.

Campbell TJ, Ackermann RR. 2010. Evaluating the emergence of tuberculosis in South Africa. Am J Phys Anthropol 141(Suppl):76.

Daniel TM. 2006. The history of tuberculosis. Respir Med 100:1862-1870. 
Dayal MR, Kegley ADT, Štrkalj G, Bidmos MA, Kuykendall KL.2009. The history and composition of the Raymond A. Dart collection of human skeletons at the University of the Witwatersrand, Johannesburg, South Africa. Am J Phys Anthropol 140:324-335.

De Souza CH, Yamane A, Pandini JC, Ceratta LB, Ferraz F, da Luz GD, Simões PW. 2014. Incidence of tuberculous meningitis in the State of Santa Catarina, Brazil. Rev Soc Bras Med Trop 47:483-489.

Donald P, Schaaf H, Schoeman J. 2005. Tuberculous meningitis and miliary tuberculosis: The Rich focus revisited. J Infect 50:193-195.

Helbling CA, Lieger O, Smolka W, lizuka T, Kuttenberger J. 2010. Primary tuberculosis of the TMJ: Presentation of a case and literature review. Int J Oral Maxillofac Surg 39:834-838.

Holloway KL, Henneberg RJ, De Barros Lopes M, Henneberg M. 2011. Evolution of human tuberculosis: A systematic review and meta-analysis of paleopathological evidence. Homo 62:402458.

Holloway KL, Link K, Rühli F, Henneberg M. 2013. Skeletal lesions in human tuberculosis may sometimes heal: An aid to palaeopathological diagnoses. PLoS ONE 8:e62798.

Kanabus A. 2011. TB Statistics for South Africa | National \& provincial figures with treatment outcomes. URL: http://www.tbfacts.org/tb-statistics-south-africa.html [accessed September 2014].

Karjodkar F, Siddhartha V, Maideo A, Sontakke S. 2012. Osteomyelitis affecting mandible in tuberculosis patients. J Clin Exp Dent 4:72-76.

Karstaedt AS, Valtchanova S, Barriere R, Crewe-Brown HH. 1998. Tuberculous meningitis in South African urban adults. QJM 91:743-747.

L'Abbé EN, Loots M, Meiring JH. 2005. The Pretoria Bone Collection: A modern South African sample. Homo 56:197-205.

Naidoo K, Naidoo K, Padayatchi N, Abdool Karim Q. 2011. HIV-associated tuberculosis. Clin Dev Immunol 2011:585919.

Ortner DJ. 2003. Identification of Pathological Conditions in Human Skeletal Remains. 2nd Ed. San Diego: Academic Press. p 227-263.

Patel M, Scott N, Newlands C. 2012. Case of tuberculosis of the temporomandibular joint. Br J Oral Maxillofac Surg 50:e1-e3.

Pawlowski A, Jansson M, Sköld M, Rottenberg ME, Källenius G. 2012. Tuberculosis and HIV CoInfection. PLoS Pathog 8:e1002464.

Pfeiffer S. 1991. Rib lesions and New World tuberculosis. Int J Osteoarch 1:191-198.

Pillay Y, Mametja D, Mbengashe T, Makakole-Nene S, Banda MA, Gqwaru N, Mvusi L, Baron P, Mhlongo-Sigwebela N, Bhardwaj S, Reid A, Ntilivamunda A, Sannie B. 2013. Joint review of HIV, TB and PMTCT programmes in South Africa. October 2013, Main Report. Pretoria: Department of Health. 
Pistorius JCC, Steyn M, Nienaber WC. 1998. Two burials from Makgope - A Batswana settlement in the Bankeveld. S Afr J Ethnol 21:115-124.

Prasad KC, Sreedharan S, Chakravarthy Y, Prasad SC. 2007. Tuberculosis in the head and neck: Experience in India. J Laryngol Otol 121:979-985.

Resnick D, Niwayama G. 1988. Diagnosis of Bone and Joint Disorders. Philadelphia: Saunders.

Rippey JJ. 1994. General Pathology. Johannesburg: Witwatersrand University Press. p 175-183.

Roberts CA, Buikstra JE. 2003. The Bioarchaeology of Tuberculosis: A Global View on a Reemerging Disease. Gainesville, FL: University Press of Florida.

Rock RB, Olin M, Baker CA, Molitor TW, Peterson PK.2008. Central nervous system tuberculosis: pathogenesis and clinical aspects. Clin Microbiol Rev 21:243-261.

Schneider M, Norman R, Parry C, Bradshaw D, Plüddemann A, and South African risk assessment collaborating group. 2007. Estimating the burden if disease attributable to alcohol in South Africa in 2000. S Afr Med J 97:664-672.

Shankaragouda B, Barjatya H, Sahu U, Savadkar A. 2013. A case of tuberculous meningitis presenting with cognitive defects. Int J Nutr Pharmacol Neurol Dis 3:388-391.

Sheikh S, Pallagatti S, Gupta D, Mittal A. 2012. Tuberculous osteomyelitis of mandibular condyle: A diagnostic dilemma. Dentomaxillofacial Radiol 41:169-174.

Steyn M, Scholtz Y, Botha D, Pretorius S. 2013. The changing face of tuberculosis: Trends in tuberculosis-associated skeletal changes. Tuberculosis 93:467-474.

Van den Bos F, Terken M, Ypma L, Kimpen JLL, Nel ED, Schaaf HS, et al. 2004. Tuberculous meningitis and miliary tuberculosis in young children. Trop Med Int Health. 9:309-313.

Vigorita VJ. 2008. Orthopaedic Pathology. Baltimore, MD: Lippincott Williams \& Wilkins.

Wilbur AK, Bouwman AS, Stone AC, Roberts CA, Pfister LA, Buikstra JE, Brown TA. 2009. Deficiencies and challenges in the study of ancient tuberculosis DNA. J Archeol Sci 36:1990-1997.

Wirth T, Hildebrand F, Allix-Béguec C, Wölbeling F, Kubica T, Kremer K, van Soolingen D, RüschGerdes S, Locht C, Brisse S, Meyer A, Supply P, Niemann S. 2008. Origin, spread and demography of the Mycobacterium tuberculosis complex. PLoS Pathog 4:e1000160. 